\title{
REVIEW \\ Synthesis of Block, Graft and Star Polymers from Inorganic Macroinitiators
}

\author{
Krzysztof Matyjaszewski, ${ }^{*}$ Peter J. Miller, Eric Fossum and Yoshiki Nakagawa \\ Department of Chemistry, Carnegie Mellon University, 4400 Fifth Avenue, Pittsburgh, PA 15213, USA
}

Recent advances in the synthesis of block, graft and star polymers containing inorganic macromolecular species are described. Anionic copolymerization techniques were used in the formation of diblock copolymers of poly(styreneblock-methylphenylsilylene) and poly(isopreneblock-methylphenylsilylene) by the ring-opening polymerization of 1,2,3,4-tetramethyl-1,2,3,4tetraphenylcyclotetrasilane initiated by living anionic polystyrene and isoprene respectively. Hydrosilation of an attachable initiator onto telechelic vinyl- or hydrosilyl-terminal or -pendant poly(dimethylsiloxane) (PDMS) yielded a PDMS macroinitiator. This macroinitiator was used in atom transfer radical polymerization (ATRP) of styrene and isobornyl acrylate to produce $\mathrm{ABA}$ triblock copolymers. As a model for graft copolymers from a polyphosphazene backbone, chemical transformation of hexachlorocyclotriphosphazene resulted in hexafunctional molecules containing either benzyl bromide or bromopropionyl moieties. The initiator 1,1,3,3,5,5-hexakis[4-(2bromopropionyloxymethyl)phenoxy]cyclotriphosphazene was used in the ATRP of styrene to yield a polymer with a narrow, monomodal molecular weight distribution. Chain extension of this star polymer with isobornyl acrylate is also described. (C) 1998 John Wiley \& Sons, Ltd.

Keywords: polysilanes; poly(dimethylsiloxane); polyphosphazenes; atom transfer radical polymerization; controlled/'living' radical polymerization

Received 2 September 1997; accepted 7 November 1997

\footnotetext{
* Correspondence to: K. Matyjaszewski, Department of Chemistry, Carnegie Mellon University, 4400 Fifth Avenue, Pittsburgh, PA 15213, USA.

Contract/grant sponsor: National Science Foundation.

Contract/grant sponsor: ATRP Consortium.
}

\section{INTRODUCTION}

One of the most important elements in the production of copolymers is control over the polymerization reaction. If the process can be manipulated so that the number of growing chains is constant and that chain transfer or termination reactions are avoided (or eliminated), then the functional group at the polymer terminus will be conserved, allowing for additional chemistry to take place. Such transformation reactions can result in production of a macroinitiator which can initiate polymerization of a different monomer, thereby producing block copolymers. If a difunctional initiator is used, the same technique can be applied toward triblock copolymers. Furthermore, use of a functional group on a monomer in conjunction with another monomer in a statistical copolymerization results in pendant species which can be transformed to initiate polymerization toward graft copolymers. With such techniques the combinations and architectures of the copolymers can be tailored to yield materials with properties that meet particular needs.

Of particular interest are copolymers that contain an inorganic block. Inorganic polymers generally possess properties that are different from carbonbased polymers. ${ }^{1}$ The desire to produce block and graft copolymers from inorganic and organic blocks is generally pursued to exploit the best properties of the individual materials and generate new classes of compounds. For example, polysilylenes (polysilanes) possess unique electronic and optical properties due to $\sigma$-bond delocalization along the silicon backbone, giving them potential applications in electronics and reprographics. Another example is polysiloxanes, which possess high oxygen permeability and favorable water and weather resistance. Finally, polyphosphazenes have a broad range of physical properties leading to applications in biomedicine as well as flame retardance based on the substituents bonded to phosphorus.

For carbon-based vinyl monomers, controlled polymerization has traditionally been achieved by 
Poly(styrene-block-methylphenylsilane)<smiles>C=Cc1ccccc1</smiles>

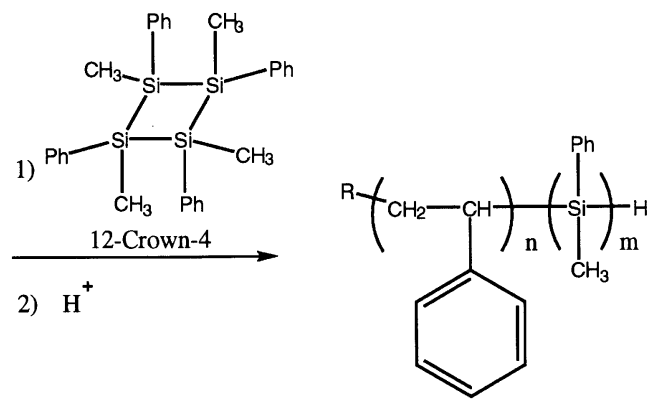

Poly(isoprene-block-methylphenylsilane)<smiles>C=CC(=C)C</smiles>

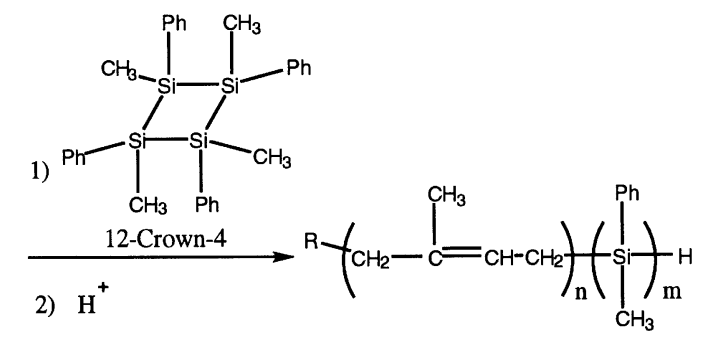

Scheme 1 Synthesis of block copolymers of PMPS with styrene (top) and isoprene (bottom) by anionic ring-opening polymerization.

ionic mechanisms. ${ }^{2}$ For example, the living anionic polymerizations of styrene and methyl methacrylate are quite common, resulting in preservation of polymer functionality. However, like the inorganic analogues, polymerization by ionic mechanisms is limited to a rather narrow class of monomers under conditions of the most stringent purity. Therefore, the desire to develop a controlled free radical polymerization system has driven research in the area for the last decade. One result of this has been atom transfer radical polymerization (ATRP). ${ }^{3,4}$ When an activated alkyl halide is stirred with a vinyl monomer in the presence of a copper catalyst, well-defined polymers are obtained with predetermined functionality and molecular weight, making them ideal for the synthesis of a variety of copolymers. The key to control is a rapid equilibrium between active and dormant propagating species. Maintenance of a low steady-state concentration of radicals ensures that termination reactions are limited to nearly insignificant values until very high monomer conversions are attained. So far, ATRP has been demonstrated to provide controlled polymerizations of monomers such as styrenes, ${ }^{5-8}$ acrylates, ${ }^{4}$ methacrylates ${ }^{3,9,10}$ and acrylonitrile. $^{11}$

In this paper we discuss recent advances made in our laboratory to produce novel copolymers and architectures based on the union between inorganic and organic macromolecular species. As the paper shows, the two primary synthetic methods are living anionic polymerization and ATRP.

\section{DISCUSSION}

\section{Block copolymers of polysilanes with vinyl-based polymers}

The most common method of producing polysilanes, the Wurtz reductive coupling of dichlorosilanes with alkali metals, ${ }^{12}$ does not provide the control over the polymerization necessary for functionalization of the chain-end toward block copolymers. Using this mode of synthesis, substitution reactions on the phenyl rings of poly (methylphenylsilylene) (PMPS) has resulted in graft copolymers with poly(tetrahydrofuran) and poly

Appl. Organometal. Chem. 12, 667-673 (1998) 
Table 1 Molecular-weight data for block copolymers containing polysilanes and vinyl-based carbon monomers

\begin{tabular}{lcccccrr}
\hline Entry & Type & $\mathrm{A}$ & $\mathrm{M}_{n, \mathrm{~A}}{ }^{\mathrm{a}}$ & $M_{\mathrm{w}} / M_{\mathrm{n}}$ & $\mathrm{B}$ & \multicolumn{1}{c}{$M_{n, \text { tot }}{ }^{\mathrm{a}}$} \\
\hline 1 & $\mathrm{AB}$ & Styrene & 2400 & 1.06 & $(\mathrm{MePhSi})_{4}{ }^{\mathrm{b}}$ & 13,900 \\
2 & $\mathrm{AB}$ & Styrene & 4700 & 1.05 & $(\mathrm{MePhSi})_{4}$ & 9700 \\
3 & $\mathrm{AB}$ & Styrene & 5400 & 1.05 & $(\mathrm{MePhSi})_{4}$ & 26,400 & 1.34 \\
4 & AB & Isoprene & 3680 & 1.13 & $(\mathrm{MePhSi})_{4}$ & 13,360 \\
\hline
\end{tabular}

a $S E C$ relative to polystyrene standards.

b 1,2,3,4-Tetramethyl-1,2,3,4-tetraphenylcyclotetrasilane.

(methyl methacrylate) ${ }^{13}$ To date the best method of controlled polymerization of polysilanes has been the anionic ring-opening polymerization of $1,2,3,4-$ tetramethyl-1,2,3,4-tetraphenylcyclotetrasilane. ${ }^{14}$ Using this technique, the synthesis of block copolymers of PMPS with organic-based polymers is illustrated in Scheme 1 for styrene and isoprene. ${ }^{15}$ In the polymerizations the organic block is polymerized first, since those processes obey 'living' characteristics. No transformation of the active site is necessary in the reactions since both polystyryl-lithium and polyisoprenyl-lithium will initiate ring opening of the cyclotetrasilane. However, in benzene the resulting silyl-lithium species exists as a tight ion pair and, as a result, does not possess sufficient nucleophilicity to open subsequent silicon rings. The presence of 12-crown-4 generates a loose ion pair and a more reactive silyl anion which facilitates ring-opening polymerization of the remaining cyclotetrasilanes. In both of the polymerizations, addition of the cyclotetrasilane and crown ether to a solution of the organic polymer resulted in a clean shift of the sizeexclusion chromatography (SEC) trace to highermolecular-weight with only a small tail toward lower-molecular-weight species. This indicates that the efficiency of initiation of the first block toward the second is quite high, e.g. greater than $70 \%$ in the<smiles>C[SiH](C)OS(C)(C)C</smiles>
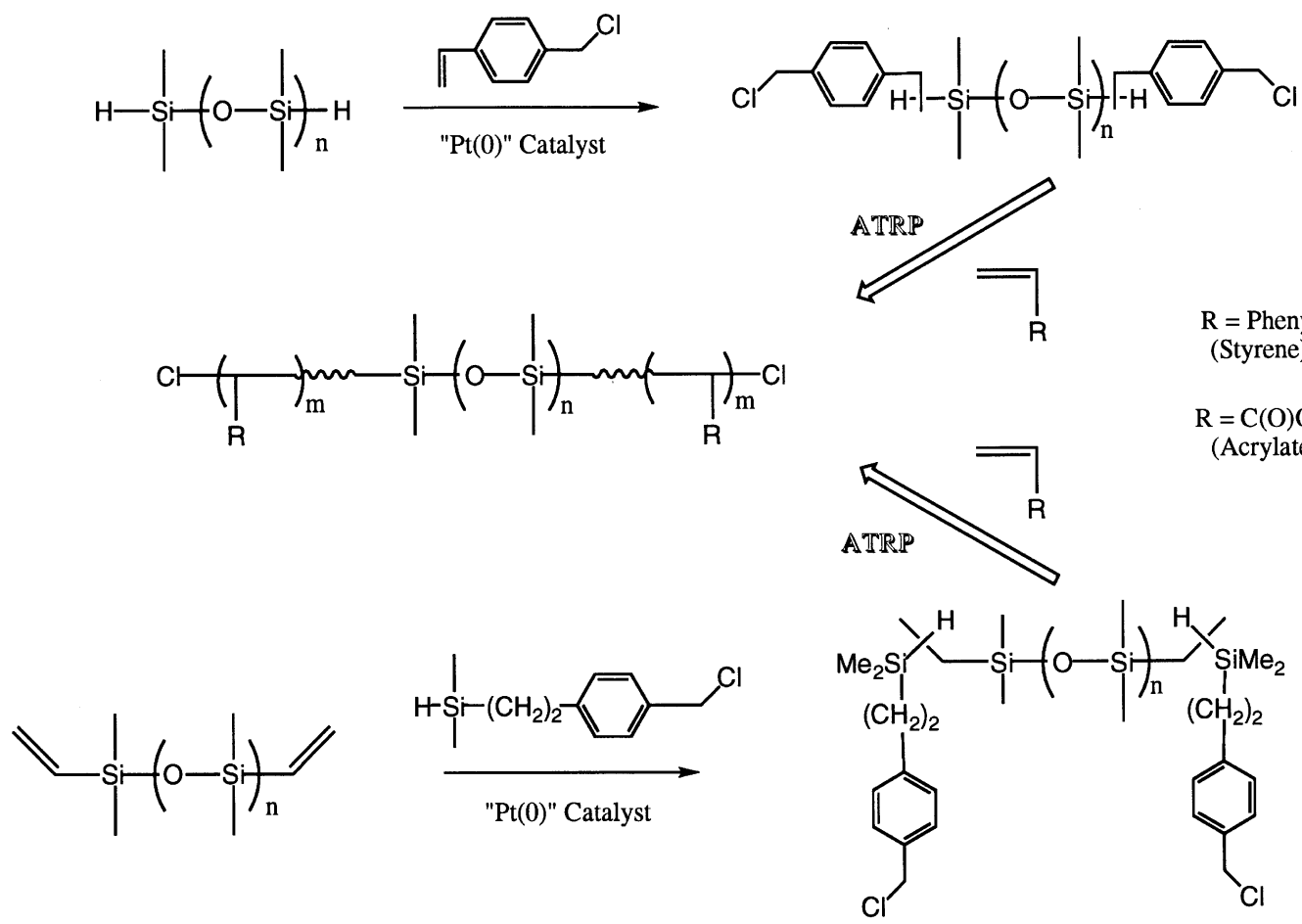

Scheme 2 General method of synthesis of PDMS block copolymers using ATRP. 
Table 2 Molecular-weight data for block and graft copolymers originating from poly(dimethylsiloxane) macroinitiators

\begin{tabular}{|c|c|c|c|c|c|c|c|}
\hline Entry & Type & A & $M_{\mathrm{n}, \mathrm{A}}{ }^{\mathrm{a}}$ & $M_{\mathrm{w}} / M_{\mathrm{n}}$ & $\mathrm{B}$ & $M_{\mathrm{n}, \mathrm{tot}}^{\mathrm{a}}$ & $M_{\mathrm{w}} / M_{\mathrm{n}}$ \\
\hline 1 & BAB & PDMS & 4485 & 1.32 & Styrene & 17020 & 1.33 \\
\hline 2 & BAB & PDMS & 9800 & 2.29 & Styrene & 20700 & 1.61 \\
\hline 3 & BAB & PDMS & 4485 & 1.32 & Isobornyl acrylate & 13610 & 1.64 \\
\hline 4 & $\mathrm{~A}-g-\mathrm{B}^{\mathrm{b}}$ & PDMS & 6600 & 1.76 & Styrene & 14800 & 2.10 \\
\hline
\end{tabular}

a SEC relative to polystyrene standards.

${ }^{\mathrm{b}}$ Graft copolymer.

case of polystyrene. Examples of block copolymers of polystyrene and polyisoprene with PMPS are given in Table 1 . The increase in polydispersity of the block copolymer relative to the macroinitiator reflects the presence of residual homopolymer which did not participate in block copolymerization, as well as the non-living nature of the ringopening polymerization of the cyclotetrasilane. Nevertheless, precipitation of the products into solvents selective for only one of the blocks demonstrated that block copolymers, rather than a mixture of homopolymers, had been produced.

The solid-state morphology of diblock copolymers of polystyrene and PMPS was probed by transmission electron microscopy (TEM) and scanning force microscopy (SFM). ${ }^{16}$ Microphase separation was confirmed by the observation of cylinders of PMPS in a polystyrene matrix on the TEM micrograph. Furthermore, when the block copolymer was placed in 1,4-dioxane (a selective

A<smiles>OCCc1ccc(OP2(Oc3ccc(CO)cc3)=NP(Oc3ccc(CCO)cc3)(Oc3ccc(CCO)cc3)=NP(Oc3ccc(CBr)cc3)(Oc3ccc(CBr)cc3)=NP(Oc3ccc(CO)cc3)(Oc3ccc(CO)cc3)=N2)cc1</smiles>

B<smiles>OCc1ccc(OP2(Oc3ccc(CO)cc3)=NP(Oc3ccc(CO)cc3)(Oc3ccc(CO)cc3)=NP(Oc3ccc(CO)cc3)(Oc3ccc(CO)cc3)=N2)cc1</smiles>
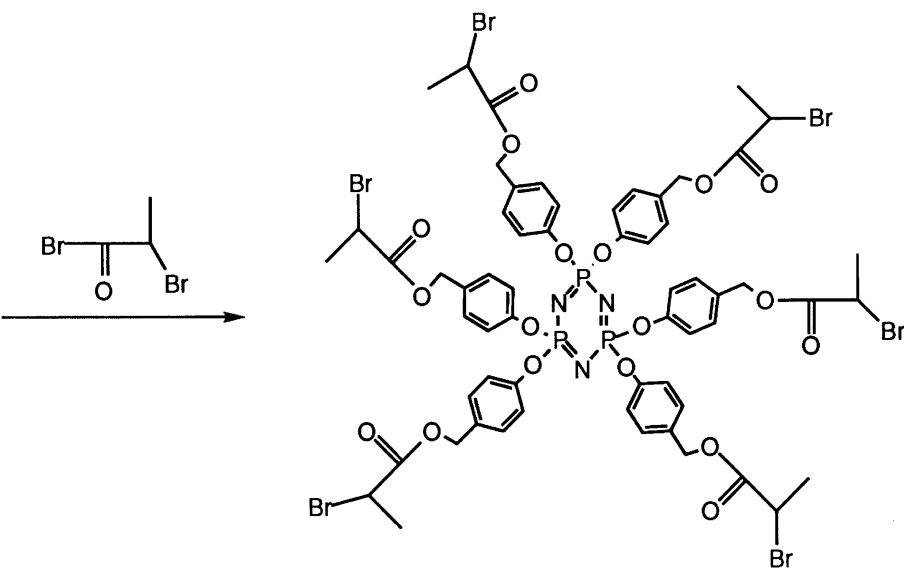

Scheme 3 Synthesis of macroinitiators 1,1,3,3,5,5-hexakis(4-bromomethylphenoxy)cyclotriphosphazene (A) and 1,1,3,3,5,5-hexakis[4-(2-bromopropronyloxymethyl)phenoxy]cyclotriphosphazene (B). 
solvent for the styrene block) and cast onto a mica surface, formation of micelles was observed by SFM, again in confirmation of microphase separation.

\section{Block and graft copolymers of poly(dimethylsiloxane) with vinyl- based polymers}

The most common silicone, poly(dimethylsiloxane) (PDMS), has a $T_{\mathrm{g}}$ of $-110^{\circ} \mathrm{C}$. However, due to its low glass transition temperature the polymer is a fluid at room temperature, making it an ideal candidate for modification by a block or graft copolymerization. This technique has been demonstrated in the block copolymerization of PDMS with numerous monomers such as styrene. ${ }^{17,18,19}$ Control over the homopolymerization of PDMS on a laboratory scale was achieved by the introduction of anionic ring-opening polymerization of hexamethylcyclotrisiloxane ${ }^{20}$ and octamethylcyclotetrasiloxane. ${ }^{21}$ The commercial route toward PDMS relies on the ring-opening polymerization of octamethylcyclotetrasiloxane. Control over terminal chain functionality in this process was brought about by addition of a terminating agent followed by fractionation of the desired polymers. In a similar fashion, copolymerization with a functionalized cyclosiloxane has resulted in PDMS with pendant functional groups.

The general route toward PDMS block copolymers using ATRP is illustrated in Scheme 2. Commercially available PDMS containing either hydrosilyl or vinyl terminal species was reacted with a benzyl chloride-functionalized attachable initiator by hydrosilation with Karstedt's catalyst. ${ }^{22}$ The isolated polymer was then capable of initiating ATRP of vinyl monomers in the presence of a copper chloride/4,4'-di(5-nonyl)-2,2'-bipyridine complex. $^{23,24}$ Table 2 shows typical examples of the ATRP of styrene or isobornyl acrylate from the macroinitiator. The polymerization proceeded with linear first-order kinetics and molecular weight increased linearly with conversion as expected for living polymerizations. The high degree of control associated with ATRP resulted in a decreased polydispersity of the block copolymer relative to the macroinitiator for higher-molecular-weight PDMS. When the ratio of polystyrene to PDMS was increased, the material ranged from a rubber to a thermoplastic elastomer to a plastic. For isobornyl acrylate, the observed increase in polydispersity is currently under investigation. The known incompatibility of PDMS in copolymers with (meth)a- crylates ${ }^{18}$ may also be responsible for problems in acrylate polymerizations.

Entry 4 in Table 2 shows the formation of a graft copolymer of polystyrene from a PDMS backbone. Using the methodology described in Scheme 2, pendant vinyl-functionalized PDMS was converted to the macroinitiator. When polystyrene was grown from the macroinitiators by ATRP, the polydispersity increased from 1.76 to 2.10 . The reason is that a variable number of vinyl moieties per chain results from the condensation method of producing the PDMS. Had each chain contained exactly the same functionality, a decrease in polydispersity would have been expected upon addition of styrene by ATRP.

\section{Star polymers from cyclotriphosphazene initiators}

A final example of an inorganic polymer is polyphosphazene. Controlled polymerization techniques have allowed the production of polyphosphazene/polyphosphazene block copolymers. ${ }^{25,26}$ There is evidence for grafting from ${ }^{27}$ or onto ${ }^{28}$ polyphosphazene backbones but none of the work cited so far incorporates the combination of the wide variety of monomers possible and the manipulation of chain length that controlled free radical polymerization provides. The traditional, non-controlled method for the production of polyphosphazenes is the ring-opening polymerization of hexachlorocyclotriphosphazene. Nucleophilic substitution reactions at phosphorus with either alkoxy or aryloxy substituents then provides the desired materials. Due to the vigorous polymerization conditions branching can occur, leading to ill-defined structures with broad polydispersities. Graft copolymers produced from such a backbone would be subject to the same limitations. Chang et al. explored a model system where hexachlorocyclotriphosphazene was converted to hexakis(4chloromethylphenoxy)cyclotriphosphazene. ${ }^{29}$ In the reaction sequence, hexachlorocyclotriphosphazene was subjected to a nucleophilic displacement reaction with $p$-hydroxybenzaldehyde to produce hexakis(4-formylphenoxy)cyclotriphosphazene.

This product was then reduced with sodium borohydride to the corresponding benzyl alcohol. Conversion of the hydroxyl group with chlorine by means of thionyl chloride yielded hexakis(4chloromethylphenoxy)cyclotriphosphazene. This material was then used in ring-opening polymerization of oxazoline to produce the six-armed star polymer. $^{29,30}$

Appl. Organometal. Chem. 12, 667-673 (1998) 


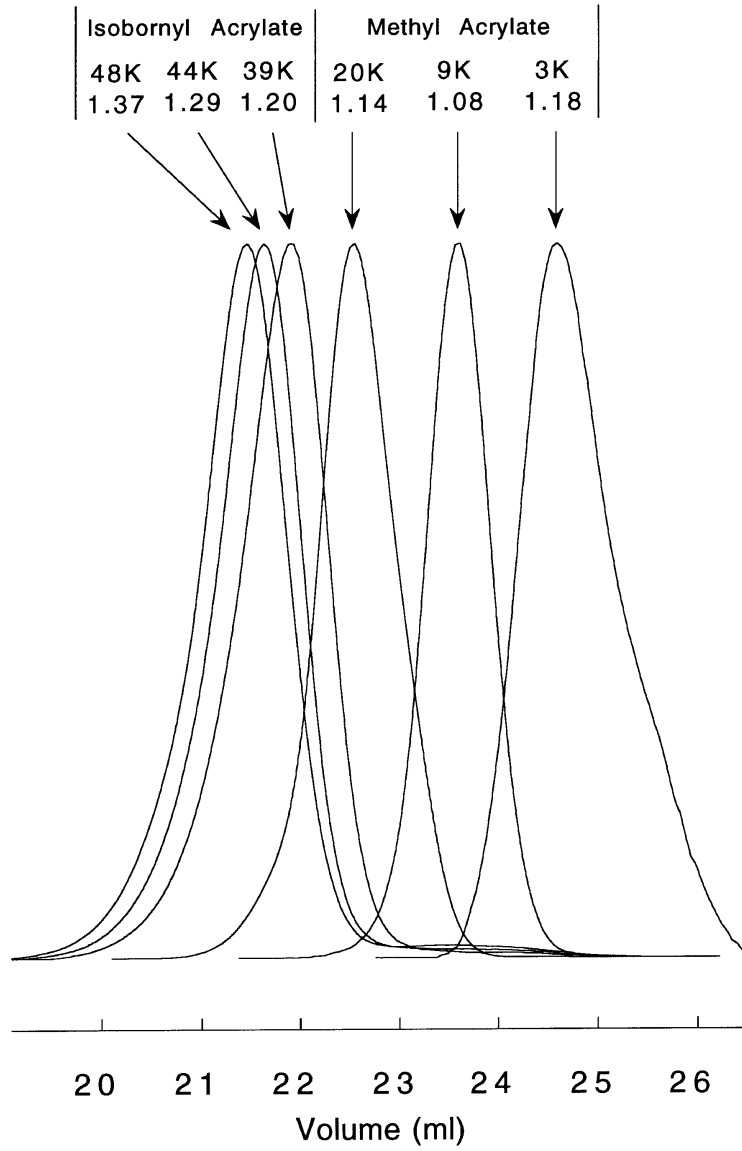

Figure 1 SEC traces for the ATRP of methyl acrylate followed by isobornyl acrylate from hexakis[4(2-bromopropionyloxymethyl)phenoxy]cyclotriphosphazene. Top number: $M_{\mathrm{n}}$ $\left(\mathrm{k}=10^{3}\right)$ bottom number: $M_{\mathrm{w}} / M_{\mathrm{n}}$.

The impetus for star polymers was to serve as a model reaction for ATRP of graft copolymers from a polyphosphazene backbone. In our laboratory, the Chang procedure was utilized to produce the hexafunctional benzyl alcohol. From this compound 1,1,3,3,5,5-hexakis(4-bromomethylphenoxy)cyclotriphosphazene and 1,1,3,3,5,5-hexakis [4-(2-bromopropionyloxymethyl)phenoxy]cyclotriphosphazene were synthesized as shown in Schemes 3(A) and (B) respectively. In Scheme 3(A) formation of the product was achieved by bromination of the benzyl group using phosphorus tribromide. The initiator was recrystallized as a white colorless solid. Attachment of the bromopropionyl group in Scheme 3(B) was facilitated by esterification of the alcohol with 2-bromopropionyl bromide. Unlike the benzyl bromide-functionalized initiator, this material was isolated as an oil; crystallization was not observed, presumably because of the multiple stereocenters associated with each bromopropionyl group.

The initiator 1,1,3,3,5,5-hexakis[4-(2-bromopropionyloxymethyl)phenoxy]cyclotriphosphazene was used in the ATRP of methyl acrylate. Linear first-order kinetics was observed. However, a deviation from the predicted molecular weight was found. Since a lower-molecular-weight peak associated with initiation by chain transfer to monomer was not seen on the SEC traces, the reason for the discrepancy was ascribed more to differences in hydrodynamic volume of the methyl acrylate star relative to the linear polystyrene standards used to construct the calibration curve. The polymer was isolated and used in an ATRP chain extension experiment with isobornyl acrylate. Figure 1 shows the SEC curves for the combined experiments. Formation of the star-block copolymer was confirmed by progressive increases of the SEC traces toward higher molecular weight species.

\section{CONCLUSION}

By various synthetic techniques, well-defined $A B$ and BAB block copolymers were produced, combining organic and inorganic materials. The AB diblock copolymers poly(styrene-blockmethylphenylsilylene) and poly(isoprene-blockmethylphenylsilylene) were synthesized by the addition of 1,2,3,4-tetramethyl-1,2,3,4-tetraphenylcyclotetrasilane to a solution of polystyryl-lithium or polyisoprenyl-lithium respectively. By chemical transformation techniques, vinyl- or hydrosilylfunctionalized poly(dimethylsiloxane) was made to react with an attachable initiator to produce PDMS containing benzyl chloride moieties. These macroinitiators were then used in atom transfer radical polymerization to produce BAB triblock copolymers with styrene and isobornyl acrylate along with graft copolymers of styrene. Finally, as a model for graft copolymers from a polyphosphazene backbone, hexafunctional initiators of cyclotriphosphazene containing either bromopropionyl or benzyl bromide substituents were synthesized. ATRP of methyl acrylate using the initiator 1,1,3,3,5,5hexakis[4-(2-bromopropionyloxymethyl)phenoxy] cyclotriphosphazene proceeded in a controlled fashion, yielding a polymer with a narrow, mono- 
modal molecular-weight distribution. The purified polymer was then chain-extended with isobornyl acrylate to produce a multiblock star polymer.

Acknowledgments The authors acknowledge the industrial members of the ATRP Consortium for financial support. E.F. and P.J.M. acknowledge the National Science Foundation for partial support of this research. Y.N. acknowledges support from the Kaneka Corporation. The General Electric Corporation is gratefully acknowledged for donation of several samples of PDMS

\section{REFERENCES}

1. J. E. Mark, H. R. Allcock and R. West, Inorganic Polymers, Prentice-Hall, Englewood Cliffs, NJ, 1992.

2. O. Webster, Science 251, 887 (1991).

3. J.-S. Wang and K. Matyjaszewski, Macromolecules 28, 7901 (1995).

4. J.-S. Wang and K. Matyjaszewski, J. Am. Chem. Soc. 117, 5614 (1995).

5. T. E. Patten, J. Xia, T. Abernathy and K. Matyjaszewski, Science 272, 866 (1996).

6. K. Matyjaszewski, T. E. Patten and J. Xia, J. Am. Chem. Soc., 119, 674 (1997).

7. V. Percec and B. Barboiu, Macromolecules 28, 7970 (1995).

8. J. Qiu and K. Matyjaszewski, Macromolecules 30, S643 (1997).

9. T. Grimaud and K. Matyjaszewski, Macromolecules 30, 2216 (1997).

10. D. M. Haddleton, C. B. Jasieczek, M. J. Hannon and A. J. Shooter, Macromolecules 30, 2190 (1997).

11. K. Matyjaszewski, S. Jo and H. Paik, Macromolecules 30, 6398 (1997).

12. R. West, in: Comprehensive Organometallic Chemistry II, Abel, E. W., Stone, F. G. A. and Wilkinson, G. (eds), Elsevier Science, New York, 1995, Vol. 2, p.77.

13. K. Matyjaszewski, J. Hrkach, H.-K. Kim and K. Ruehl, in: Silicon-Based Polymer Science, Zeigler, J. M. and Fearon, F. W. G. (eds), ACS Symp. Ser. No. 224, American Chemical Society, Washington, DC, 1990.
14. M. Cypryk, Y. Gupta and K. Matyjaszewski, J. Am. Chem. Soc. 113, 1046 (1991).

15. E. Fossum, J. A. Love and K. Matyjaszewski, J. Organomet. Chem., 499, 253 (1995).

16. E. Fossum, K. Matyjaszewski, S. S. Sheiko and M. Möller, Macromolecules 30, 1765 (1997)

17. J. V. Crivello, D. A. Conlon and J. L. Lee, J. Polym. Sci., Polym. Chem. Ed. 24, 1197 (1986).

18. C. P. R. Nair and G. Clouet, Macromolecules 23, 1361 (1990)

19. R. C. Kumar, M. H. Andrus Jr, R. R. Dueltgen and M. H. Mazurek, ACS Polym. Prepr. 35, 786 (1994).

20. S. Boileau, in: ACS Symp. Ser. No. 286, American Chemical Society, Washington, DC, 1985 p. 8.

21. A. Molenberg and M. Möller, Macromol. Rapid Commun. 16, 449 (1995).

22. P. B. Hitchcock, M. F. Lappert and N. J. W. Warhurst, Angew. Chem., Int. Ed. Engl. 30, 4 (1991).

23. Y. Nakagawa, P. Miller, C. Pacis and K. Matyjaszewski, ACS Polym. Prepr. 38, 701 (1997).

24. Y. Nakagawa, P. J. Miller and K. Matyjaszewski, Polymer 39, S163 (1998).

25. K. M. Matyjaszewski, K. Moore and M. L. White, Macromolecules 26, 6741 (1993).

26. H. R. Allcock, S. D. Reeves, J. M. Nelson and C. A. Crane, Macromolecules 30, 2213 (1997).

27. P. Wisian-Neilson, in: Inorganic and Organometallic Polymers II, Wisian-Neilson, P., Allcock, H. R. and Wynne, K. J. (eds), ACS Symp. Ser. No. 572, American Chemical Society, Washington, DC, 1994, p. 246.

28. M. Gleria, F. Minto, P. Bortolus, G. Facchin and R. Bertani, in: Inorganic and Organometallic Polymers II, WisianNeilson, P., Allcock, H. R. and Wynne, K. J. (eds), ACS Symp. Ser. No. 572, American Chemical Society, Washington, DC, 1994, p. 279.

29. J. Y. Chang, H. J. Ji, M. J. Han, S. B. Rhee, S. Cheong and M. Yoon, Macromolecules 27, 1376 (1994).

30. For a review of star polymer syntheses, see Simms, J. A.; Spinelli, H. J. in: Macromolecular Design of Polymeric Materials, Hatada, K., Kitayama, T. and Vogl, O. (eds), Marcel Dekker, New York, 1997, p. 379, and references therein. 